\title{
From the Holistic Governance Perspective to Study Multidimensional Analysis of China's Food Safety Supervision System
}

\author{
Zhaorui Feng \\ Quality Development Institute \\ Kunming University of Science and Technology \\ WuHua District, XueFu Road, PRC. 650093 \\ fzr86@163.com \\ Shaowei Zhang \\ Education research Institute in Qinhua University \\ Yunnan Long Spring Education Group \\ 156520082@qq.com
}

\author{
Shaohua Xu \\ Journal of Kunming University of Science and Technology \\ Kunming University of Science and Technology \\ 834046878@qq.com
}

Sun Min

Yunnan Macroeconomic Research Institute sunmin8142@163.com

\begin{abstract}
In order to put forward holistic governance analysis framework, implement multi-dimensional analysis of China's food safety supervision system, this study on the basis on the relevant research perspectives of holistic governance theory, from the value chain between market subjects, the whole process involved in food safety and interests relationship between regulatory main body three dimensions to discuss the regulation characteristics of market related main subjects of China's food safety regulation system, the subjective characteristics and damage mechanism of related process, the cooperative characteristics and non-cooperative dilemma of relevant regulatory department. Based on the key points from analyzed three dimensions above, this study proposed the "four in one" governance framework to promote the integrity innovation of China's food safety regulatory system from integrating governance structure, coordinating interest conflicts, integrating action accountability and multiple regulatory information four aspects.
\end{abstract}

Keywords—food safety; regulatory system; holistic governance; multidimension

\section{INTRODUCTION}

Food safety management system refers to the division of responsibilities, the distribution of regulatory authority, the organization set up, the development of laws and regulations and other elements of the organic system during the process of the food safety supervision of the national administrative system. In view of the fact that food safety supervision constantly exposes regulatory fragmentation, the introduction of the holistic governance theory in food safety supervision system can provide an explanatory framework for food safety supervision, which is conducive to build the food safety supervision system under the Holistic government. Based on this, Li Bojun, Ma Xiaofang, Liu Yaping and other scholars ${ }^{[1-6]}$ analyzed and summarized a number of domestic and overseas' food safety regulatory systems reform experience and they thought that promoting the Holistic reform of China's food safety regulatory system is a possible way to respond to the current dilemma of food safety Supervision. However, most scholars at present only regard the connotation and extension of holistic governance concept as the method or tool of food safety supervision, discussing the reference or application of the holistic governance model of food safety supervision from the theoretical level, and did not propose the normative analysis framework of the holistic governance theory.

On the basis of research results of relevant public management theories and economic analysis methods of Kirkbride, Haina and Tao ${ }^{[7-10]}$, this article thinks that it is possible to further clarify the analytical framework of holistic governance in food safety supervision system .In view of tracing the causes of "fragmentation" during the process of food safety supervision, this paper analyzes the behavior of multi-regulators and their stakeholders which is associated with the process of food safety supervision. This article relies on combing and optimizing interrelations of three dimensions of mercerization, informationization and synergeticization to explore the new ideas, new directions and new models of the reform of food safety regulatory system under the guiding of holistic governance theory. In view of this, this study from the food trade value chain, the whole process of food production transportation and consumption, the relationship among multilevel main body of food regulatory, clarify the Holistic governance points of food safety regulatory system to further promote China's food safety supervision Institutional innovation to provide a certain theoretical and methodological support.

\section{ANALYSIS OF FOOD SAFETy REgULATORY SySTEM ON THE BASIS OF VALUE CHAIN}

The food market under the integrated governance includes consumers, food enterprises, governmental supervise agents and other parties. These market players have to adjust the way 
of participation in the market on the basis of their own value demand preferences and supply capacity, which have complex impacts on the overall food safety supervision.

\section{A. The Characteristics of the Relevant Regulatory Main Body Under the Value Chain Perspective}

The behavior regulation's characteristics of food production enterprises in the view of value chain is mainly that the enterprise food safety management behavior is affected by its scale and organization, market structure, competition pattern, market development degree, supervision intervention degree, supervision system integrity degree and way of supervision. The behavior regulation's characteristics of food consumers' in the view of value chain is mainly that the consumers lack of food safety knowledge and skills, have low willingness to buy high-specification products, have more conservative consumer habits, have limited dynamics of market information. The behavior regulation's characteristics of government in the view of value chain is mainly that the main body of regulation is not clear, the difficulty to balance interests among different departments, the difficulty of sharing information resources and the supervision depends on the law enforcement.

\section{B. The Market Game of the Relevant Players from the Perspective of the Value Chain}

Various stakeholders of the market segments during the process of food from the field to the table are seeking to maximize the interests during the long-term mutual cooperation and mutual competition that they formed a relatively stable relationship during the game increasingly.

1) The behavior game between the Consumer and food production enterprise.

The following assumptions are made as relevant transaction information on the behavior of food consumers and food producers: (1) the strategy of food consumers is to consume or not to consume food, and the strategy of food producers is to produce high quality food, lower quality food or not to produce. (2) If the food production enterprise produces high quality food and the consumer chooses to consume, then the utility of the two is $\mathrm{x}$, $\mathrm{y}$, if the consumer does not consume high quality food, the utility of the two is $\mathrm{z}$, 0 ; (3) If food producers produce low-quality products and consumers choose to consume, then the utility of the two actors is $\mathrm{u}, \mathrm{v}$ respectively; if consumers do not consume lowquality products, the utility of the actors is $\mathrm{W}, 0$. If the producers do not produce, then the producers and consumers get the utility of 0 . The game relationship between producers and consumers is shown in Fig 1 below.

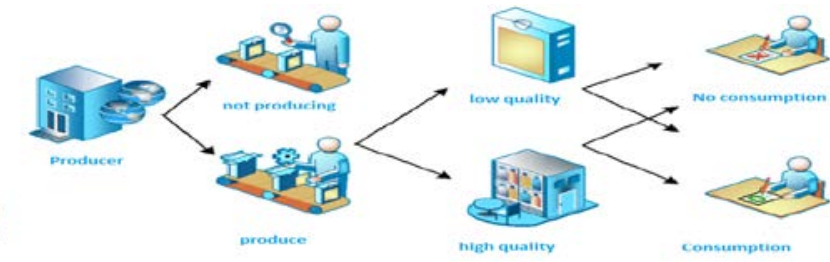

Fig. 1. Game behavior of food consumers and producers under the information asymmetry situation
The consumer who chooses consuming food has the expected utility $\mathrm{yQ}+\mathrm{v}(1-\mathrm{Q})=(\mathrm{yv}) \mathrm{Qv}$, and the consumer consumes the food only when $(\mathrm{yv}) \mathrm{Qv} \geqslant 0$, and when $\mathrm{Q} \geqslant \mathrm{v} /$ (yv), Although consumers choose to consume food, but food production enterprises due to the production process to enhance the pressure and consumer spending will inevitably choose the low-quality food. The solution at this time is not the equilibrium solution of the game, because the consumer rationality can identify food producers using information asymmetry and want only sell low-quality products behavior, at the same time, rational food production enterprises will be aware of Consumer propensity to consume. Therefore, the food production enterprises do not produce food; consumers do not consume food as both the game equilibrium solution.

2) Game behavior analysis between the government and producer.

Suppose there are two kinds of strategies for food production enterprises. They are the production of high-quality food $\mathrm{L}$ or low-quality food $\mathrm{M}$ respectively; suppose there are two strategies of the food safety regulatory authorities. They are respectively regulated $G$ and unregulated $B$. In view of the low-quality products are often pass off the fish eyes as pearls, in this assumption $S$ for food production enterprises' the total sales of products (total income), $\mathrm{C}$ for the administrative costs of food safety supervision, CL for high-quality product's production costs, CM for the production cost of low quality product, and $\mathrm{S}>\mathrm{CL}>\mathrm{CM}, \mathrm{P}$ is the penalty when the producer is found to supply a low quality product. Therefore, if the game behavior is a complete information static game, the return matrix is shown in Table 1 below.

TABLE I. GAMING MATRIX OF GAME BEHAVIOR: GAME BETWEEN FOOD SAFETY REGULATORY AUTHORITIES AND FOOD PRODUCTION ENTERPRISES

\begin{tabular}{|c|c|c|}
\hline $\begin{array}{c}\text { Food safety } \\
\text { regulatory authorities }\end{array}$ & Low quality product & $\begin{array}{c}\text { High quality } \\
\text { product } \\
\text { to produce }\end{array}$ \\
\hline Supervision & P-C,-P-CM & -C,S-CL \\
\hline Non-supervision & 0,S-CM & 0,S-CL \\
\hline
\end{tabular}

The game has no pure strategy Nash equilibrium. The Nash equilibrium of this game is related to the sales income (S) of the product, the production cost of the high quality product $\mathrm{CL}$, the production cost of the low quality product CM, the food safety administrative supervision cost $C$ and the fine $P$. The behavior of imposing heavy penalties for producing lowquality products to form high-pressure situation, which can effectively curb the production of low-quality products. The food safety supervision administrative cost is higher, which the rate of producers produce low-quality products is higher.

\section{Food Safety Regulatory Point under the View of the Value Chain}

The result of the game equilibrium above shows that consumers and food producers do not choose consuming behavior for rational consideration, and the extreme situation 
of "market collapse" occurs at this time. And government supervision, regulatory effectiveness and regulatory effect were positively correlated. The above analysis also shows that the various stakeholders in the market interact to form the market mechanism with a certain development trend. In this market mechanism, the goal as in order to respond to the market failure may lead to food safety hazards, which with social groups related to food safety governance and nongovernmental organizations in the food safety supervision and management process for the government that strengthen the food safety market order rectification and provided a great help to fill the government regulatory deficiencies, and had great significance to improve the efficiency of food safety supervision. From the perspective of regulatory costs, the degree of information asymmetry of social groups is relatively small, the costs of government regulatory and the implementation of laws and regulations will be greatly reduced. As a direct object of food consume, food-consumers have close relationship with food safety issues, whom are also the main protected objects of laws and regulations, while consumers are also closely linked with the interests of food companies. With gradual maturity of the market, consumer ideas and consumption habits gradually change and optimize that will help consumers continue to improve their food safety awareness, which is essential for the purification of food consumption environment, maintaining normal food consumption order.

\section{ANALYSIS OF FOOD SAFETY REGULATORY SYSTEM ON THE BASIS OF THE WHOLE PROCESS}

Food from primary production, sales processing, need to go through a long and complex chain of food safety supervision, which every step are likely to be able to induce food safety issues in the key nodes, such as food from the source of agricultural production/ breeding, raw materials production and processing, as the logistics of food commodities to sale of each Links. Induced food safety hazards elements are associated with the circulation of the food supply chain, and similar to the bullwhip effect, such as continuous gathering and amplification, and ultimately lead to food safety incidents.

\section{A. The Characteristics of the Relevant Subject from the Whole Process Perspective}

The main features of food production body of raw materials are that hundreds of millions of small farmers are the basic unit of agricultural production, which they decentralized, operated in the small scale with low production skills when they cooperate with enterprises, wholesalers, supermarket chains, whose interests lack of effective protection that may induce harm to the quality and safety of agricultural product. Most of the food enterprises are small, micro-food enterprises and small food workshops that accounted for about 93\% of the whole food enterprises. These food enterprises are relatively weak in production technology, resource utilization and management and because of lower threshold of entering into this industry, which have vicious internal homogeneity competition. Taking the main food distribution task in the supply chain are food stores, food supermarkets, food wholesale market, community service stores, farmers markets, convenience stores and department stores. These types of food sales subject are complex, involving many management departments and very different in sources in food channels, category specifications, quality requirements, management systems, which proposed new standard for targeted management.

\section{B. The Harm Mechanism from the Perspective of the Whole Process}

Generally speaking, all relevant stakeholders or the main responsibility body in the food supply chain are based on the characteristics of their links and the implementation of different technical specifications of quality control, so only depend on the terminal food safety and quality control cannot completely eliminate food safety hazards. Besides the food safety standard system which is implemented among the relevant subjects in the food supply chain is not the same, and the mode of sub-regulation is not conducive to improve the management efficiency.

The quality and safety of each key point in the food supply chain (each participant) directly determines the quality and safety of food. Each key point has an impact on food quality and safety and through the supply chain passing and amplifying the security risks. Therefore, each key point (each participant) of the quality and safety standards directly determines the final food safety level. As described above, food quality and safety standards lies in "the core structure" of quality and safety risk formation structure in the food supply chain, the risk of trading trust of food supply chain quality lies in the "intermediate structure" that is due to the loosening of the supply chain structure and the risk of not closing cooperate relationship among all subjects, the market risk of quality and safety in food supply chain lies in the "peripheral structure" of the circle structure, which due to the external environment attributes to food supply when it is operating. On the basis of the above cognition, the author thinks that the primary production, raw material processing, commodity circulation, food sales to the table are not only the formation of quality of food safety, but also the risk of quality safety of formation of food supply chain. Food quality and safety involves many departments, multiple links, multiple subjects, and the protection of quality of food security needs of various departments, all the main body, all aspects of close collaboration, system supervision, multi-pronged together to protect. Therefore, the mechanism of food safety hazards can reflect the multi-level needs of food safety supervision, and the ability of risk control of quality and safety of all the main bodies and links will affect the final quality of food. The risk of quality and safety of supply chain is the joint of the risks of quality and safety of agricultural products through the whole supply chain operation process, the ability risk of quality and safety of food processing, the ability risk of quality and safety of logistics and transportation and the risk of the quality and safety of circulating and selling. Therefore, the mechanism of food safety hazards from the perspective of the whole process shown in Fig 2 below. 


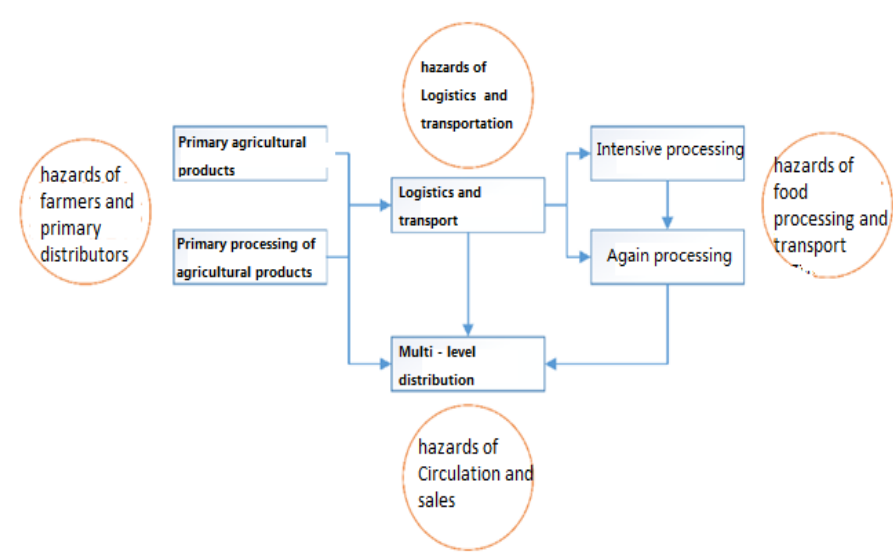

Fig. 2. The mechanism of food safety hazards from the perspective of the whole process

\section{The Point of Food Safety Supervision from the View of The Whole Process}

In order to fulfill the basic function of supervise and precontrol of risk identification of food safety, evaluation and management, it is necessary to strengthen food safety supervision technology, integrate supervision function and broaden supervision connotation. The technical methods of food safety supervision including identification and assessment of possible biochemical and physical damage in all aspects of the food chain, which give effective measures of prevention and control of food safety hazard. Integration of regulatory function is to deal with the diversification of the main sell subjects and links of food production, processing, transportation, sales to re-sort the existing regulatory content from the point of integrating the core content as the starting point to overcome regulatory deficiencies, regulatory weaknesses and regulatory conflicts to enhance the effectiveness of food safety supervision. Widen the regulatory connotation refers to bring the social supervision into the food safety supervision system, which not only increases the consumer's ability to identify food safety hazards, but also give full play to the social order and good customs, social credit and public opinion to defend food safety. In addition, the risk of food safety is not due to the backwardness of inspection and testing technology. The main reason is that the lack of system supply makes it difficult to effectively carry out food safety supervision. Therefore, it is imperative to establish a sound food safety supervision and law system, strictly enforce the market access system, strengthen food labeling management, build food safety monitoring and information dissemination system that will enhance social credit and improve consumer awareness of food safety from the overall perspective.

\section{ANALYSIS ON FOOD SAFETY SUPERVISION SYSTEM ON THE BASIS OF INTEREST RELATION}

In view of the complexity of the overall governance of food safety supervision and the value chain, the lack of integrity of the regulatory system, the lack of clarity of duties, the absence of supervision or the supervision of offside have seriously affected the effect of food safety supervision.

\section{A. The Characteristics of the Cooperation of the Supervisory Departments Based on the Interests Relation.}

The essence of cooperation among different supervisory departments of food safety is that a certain department transfers some of its scarce resources to other relevant departments, such as law enforcement power, administrative accountability, regulatory information, cooperative feasibility, etc. The status of cooperation can be expressed as the formation of the relevant departments to achieve orderly regulation of food safety in the long-term collectively agreement of action. However, the smooth implementation of the agreement, the specific implementation and process supervision and other sectors prone to opportunistic behavior and external economic effects that let the cooperation among food safety regulatory departments into difficulties. The occurrence of opportunistic behavior in food safety supervision refers to the extra transaction cost due to the lack of standardization and clarification in the collaboration among the various regulatory actors in the process of food safety supervision. Collaborative externalities in safety regulation derive from the potential differences between the potential benefits and potential cost. Based on the above, in the case of blocked of promoting joint enforcement of law, the best choice of rational food safety regulatory departments will be optimized regulatory input level and its way. However, the existence of externalities is often difficult to promote the overall regulatory effect to achieve the best social level.

\section{B. The Non - Cooperation Dilemma of the Supervisory Departments under the Interest Relation}

Due to the limited rationality of various food safety regulators and the high transaction costs associated with externalities, it is difficult for regulators in an unstable partnership to anticipate all contingencies, and the partners cannot change their cooperation on their own income approach (The formation of a changeable food safety regulatory model). On the basis of this cooperation will lead to food safety supervision caught into a series of non-cooperative dilemma ( Fig 3).

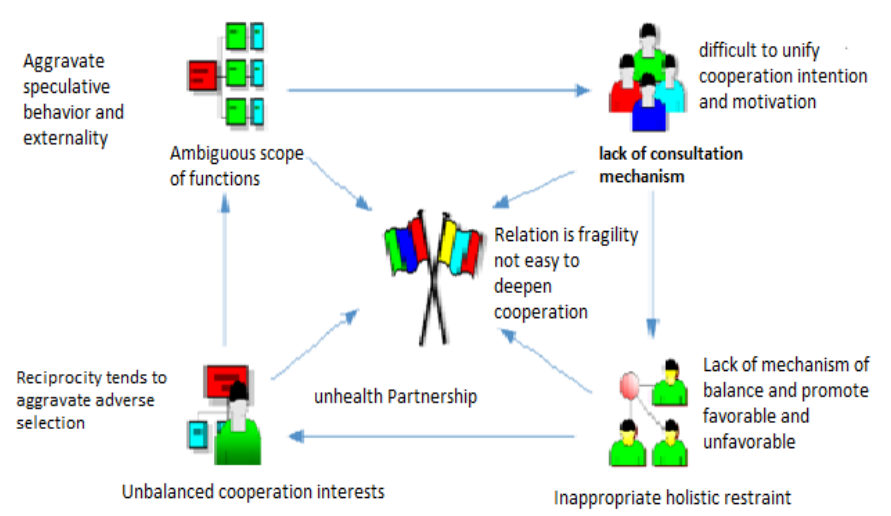

Fig. 3. Non-cooperative dilemma of food safety supervision.

Non-cooperation Dilemma 1: The scope of functions is ambiguous 
There are contradictions and conflicts between the new and old regulate systems, and lack of coordination mechanism among the regulators, which makes the boundary of the authority and jurisdiction among the regulators ambiguous. The ambiguous boundary of the functions of food safety supervision subjects will distort the disposal right of the relevant departments and increase the possibility of opportunistic behavior.

Non-cooperation dilemma 2: lack of consultation mechanism

Because the departments responsible for food safety supervision have relatively independent political status and belong to different administrative systems, they do not have an interactive platform for the exchange of resources among the regulatory bodies, which even if has the comprehensive coordination function, it is difficult to sign the contract and carry out the joint supervision of the process without enough incentives.

Non-cooperative dilemma 3: the overall constraints improperly

In order to promote the cooperation among food safety supervise departments, scientific and reasonable incentive measures should be formulated and the operation cost of the cooperation mechanism should be reduced as far as possible so as to form a stable operation governance structure. The drawbacks of enforcement of the current administrative law is multidisciplinary consultation and implementation, which makes the problem of "principal-agent" is easy to occur that makes how to design the governance structure of subject game becoming the core problem of forcing the departments to behave correctly. interests.

Non-cooperative dilemma 4: Unbalanced cooperative

The cooperative returns are unpredictable and nondeterministic, and also there are many implicit indexes that affect their cooperation effect during the cooperation process. With uncertainties of future cooperation prospects and benefits of the two parties, both sides have the motivation to take opportunistic behavior. In addition, with different efforts of different regulatory departments during the process of cooperation so that the cooperative returns show separated characteristics in time and space. Thus the external supervision of opportunism is popular, which taking the mutual benefits as the starting point, the externalities has been gradually accepted and utilized that lead to the problem of adverse selection.

Non-cooperative dilemma 5: Unhealthy cooperative relationship

The driving force of cooperation among food safety regulatory departments can be summarized as two points: First, getting the consensus on the importance of sharing resources. Second, use governmental authority to promote cooperation among the regulators from top to bottom. As needing to compete with each other for similar functions and clients, departments for their own good tend to be non-cooperation. At the same time, there is always an inherent conflict in departments between the autonomy and duty, which not only upholds the independence of the departments through avoiding participating in cooperation, but also out of duty the departmental complies with the higher order to participate in cooperation.

\section{The Key Point of Regulatory in the View of Food Safety Interests.}

Fragmentation of food safety supervision and interdepartmental cooperation dilemma are the problems that the modern public governance often needs to deal with. The key of breaking through the dilemma of inter-departmental cooperation is to design an effective food safety governance structure from the overall top level. In view of this, to deal with the dilemma of multi-department food safety regulatory need to improve the persistence of trust among the departments, fairness and standardization of law, the effectiveness of communication. Inter-departmental trust can be viewed as a resource, and the trust among food safety regulators is a consensus reached by various departments in constant consultation and interaction that the mutualfamiliarity of inter- departmental can counteract speculative behavior that may arise from trading partners. The cooperation norms and equity issues of food safety regulatory among the regulate departments related to the responsibilities, rights and interests of the regulatory authorities, are the regulatory resources and states of supervise modes that all the regulatory authorities recognized in consensus, which is a rational and relatively balanced resource exchange that emphasis the urgency of the food safety regulators to distribute the interests rationally from the side of Holistic governance. To establish a timely, effective and unimpeded communication and consultation mechanism among food safety regulators is an important prerequisite and expected result of good cooperation, which includes formal communication systems, such as departmental joint meetings as well as informal communication channels and spontaneous experience exchange of each department.

\section{THe Holistic GOVERnANCE PoIntS OF FoOd SAFETY REGULATORY SYSTEM}

Looking at the results of the previous analysis, the current food safety regulatory work in China is facing the holistic issues of poor market self-regulation ability, many regulatory links and the complex relation of related stakeholders. Combing the dimensions of the holistic governance points we can see that it is a complex systematic project to comprehensively and effectively deal with the multidimensional problems caused by the market operation during the whole process's supervision and the dilemma of the cooperation among the supervisors. The above-mentioned holistic governance needs are related to each other, it can be summarized as four aspects: integration of governance structure, coordination of inter-departmental conflicts of interests, integration of operational accountability, integration of multiple regulatory information, which the interrelated points of holistic governance as shown in Fig. 4. 


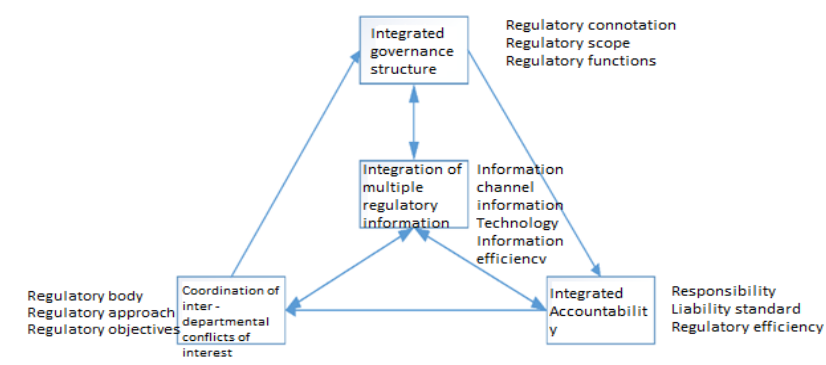

Fig. 4. Non-cooperative dilemma of food safety regulation

\section{A. Integrated governance structure}

The functional integration of the various regulatory departments is an important means to tackle the fragmentation of the new public management and other issues. The organizational structure of the government is designed to solve the problems of the public facing rather than the process management oriented. Based on that, the holistic governance of the food safety regulatory system needs to redesign a problem-oriented organizational structure. Because the current regulatory system is based on a typical bureaucratic organization that cannot effectively respond to a large number of public regulatory needs caused by market changes, and cannot handle the coordination issues among the various government regulatory departments so that the introduction of network organizational structure can deal with the existing problems of regulatory system adjustment at a certain extent, which can be effectively focus on non-core food safety regulatory content based on the outsourcing of government functions and the development of information technology, and having a promoting effect on regulatory functions, division and linking of regulatory content and the integration of regulatory relationship. According to the holistic governance theory put forward by Hicks that in order to achieve the goal of the integration of governance of China's food safety supervision, the network regulatory organizational structure of China's food safety supervision needs to gradually form a relatively stable semi-open bureaucratic organization from the integration of policy level, authority system, supervision value, operation budget, information system and personnel management.

\section{B. The Interest Conflicts Coordination among Inter- Departments}

The main body of holistic governance consists of various forms of governments or non-governmental organizations that provide public services, which are united by the way the holistic governance conceived and not affected by differences in ideology and class interests.

The holistic governance theory first advocated that the concept of Public value is the core value of holistic operation, but the holistic governance is implemented by many institutions and personnel, which cannot avoid the issues of mutual benefit. To solve the non-cooperative oriented issues of corresponding regulatory body to take the holistic operation, in fact, the effectiveness of holistic operation has a close relationship with the degree of interests of departments of operation and participation which the relationship close, urgent or not will decide whether these regulators will coordinate and cooperate with other departments. In view of this, coordinating the relation among food safety regulators, the interests of institutions, and even extending this connotation to the third-party social regulatory agencies, will be the main content of holistic governance of China's food safety regulatory system to address.

\section{The Integration of Act Accountability}

Positive and effective system of accountability of food safety supervision need to first clear the responsibility of the main regulator body and accountability standards. During the process of actual implementation of food safety governance at home and abroad, it is not easy to have a conclusion which departments should take the direct responsibility when the duties of the regulatory authorities are unclear and the authorities are not sure about the secondary departmental buck-passing. In view of this, the holistic governance of China's food safety regulatory system is facing the grim reality test of how to get balance among the vertical responsibility, horizontal responsibility and responsiveness between the controllability and efficiency, which the system should establish and improve the system of accountability, standards, policies, regulations and laws to worse the balance of the corresponding as soon as possible.

\section{Integration of Multiple Regulatory Information}

Modern information network technology for the overall management of food security provides a broad prospect, and even to some extent, the overall governance of food safety supervision can only be achieved through the escalation of information technology. The effective information in the process of food safety supervision includes the multidimensional information, such as origin traceability information, logistics information, price information, quality information and supervises factor information, etc. The information source, statistical caliber, statistical way and expression way are difficult that is not only difficult to effectively collect, organize, but more difficult to achieve systematic analysis and utilization. Therefore, drawing support from the modern information network technology to promote the collection of food safety supervision information timely, scientific analysis and effective use is the first problem to solve for integration of multiple regulatory information. At the same time, from the point of constructing the information channel system, the holistic governance of China's food safety supervision needs to achieve the integration of different levels of government, standardization and systematic in different regulatory bodies and different market participants, which is the base of promoting the integration of governance structure, the coordination of the interests among different departments and the acting accountability.

\section{CONCLUSION}

Based on the perspective of relative research of holistic governance theory, this paper applies multidimensional analytic approach to comprehensively analysis the China's 
food safety supervision system from three dimensions: the value chain among the market players, the whole process involved in food safety and the interest relationship between the regulators. This paper creatively put forward a whole four points of innovation of China's food safety regulatory system as "three integration and one coordination." This paper shows that the current domestic food safety supervision is faced with tough problems of poor market self-regulation capability, numerous regulatory links and the complex relationship between stakeholders. To solve the problems mentioned above necessarily need to strengthen the construction of the rule of law and consumer environmental protection, need to balance the subject of social regulation of information asymmetry relationship, need to open up the information transmission channels and broad the sources of information and also need to coordinate the overall regulatory functions, regulatory scope and regulatory implications from the comprehensive scope.

\section{ACKNOWLEDGMENT}

Supported by the Humanities and Social Sciences Foundation of Ministry of Education (15XJC810001) and University's talent training project of Kunming University of Science and Technology in 2016, Social Co-governance: A Study of China's Food Safety Regulation towards Holistic Governance (KKZ3201658008).

\section{REFERENCES}

[1] Li Bo jun. Food safety management system research [D]. Zhejiang Normal University, 2009.

[2] Ma Xiao fang. Deepening reform research of China's food safety supervision system [J]. Economic Research Reference, 2014 (30): 5-12.

[3] Liu Yaping.: The reform and challenge of China's food supervision system [J]. Journal of Huazhong Normal University: Humanities and Social Sciences Edition, 2009, 48 (4): 27-36.

[4] WANG Wei-dong, ZHAO Shi-qi. the improvement of China's food safety supervision system from the perspective of Food Safety Law [J]. Chinese Condiment, 2010 (6): 22-24.

[5] Liu Peng.China's Food Safety Supervision: An Empirical Study based on Institutional Change and Performance Evaluation [J]. Journal of Public Administration, 2010 (2): 63-78.

[6] YAN Hai-na, NIE Yong-hao.The Logic of Institutional Choice - The Evolution of China's Food Safety Regulation System [J]. Journal of Public Administration, 2009, 6 (3): 12-25.

[7] Kirkbride J, Letza S. Regulation, Governance and Regulatory Collibration: achieving an "holistic" approach[J]. Corporate governance: an international review, 2004, 12(1): 85-92.

[8] Haina Y. The Reform of Food Security Supervision System: Analysis Based on the Theory of Holistic Government [J]. Academic Research, 2010, 5: 009.

[9] Tao H. Study on Strategies of Institutionizing Holistic Governance[J]. Public Administration and Law, 2010, 2: 1-4.

[10] Chao L I U. The Reorganization of the Fragmented Governance on Local Public Crisis: from the View of Holistic Governance [J]. Journal of Jishou University (Social Sciences Edition), 2009, 2: 016. 